\title{
CAN INVASIVE SNAILS REDUCE PARASITISM IN NATIVE SNAILS? AN EVALUATION OF THE DILUTION EFFECT HYPOTHESIS
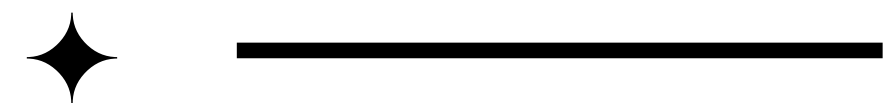 \\ AMY KRIST \\ $\uparrow$ LARAMIE, WY
}

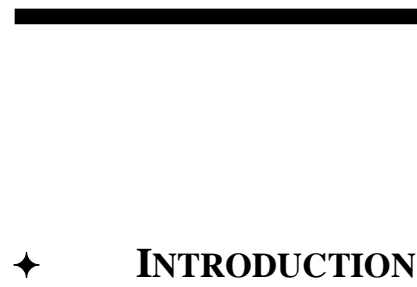

The dilution effect hypothesis states that any non-target host species can act as a decoy or resistant host to disease or parasite transmission stages, thereby reducing the negative effects of the diseases or parasites on the coevolved host (Prenter et al. 2004, Johnson and Thieltges 2010). Invasive species are often resistant to parasites in the new ecosystem because native parasites have not evolved to be able to successfully infect them (Prenter et al. 2004). In laboratory experiments, Kopp and Jokela (2007) found the presence of the invasive snail, Lymnaea stagnalis, acted as a resistant host for trematode infection resulting in reduced infection rates in the native snail. Similarly, the presence of the invasive American slipper limpet, Crepidula foricata, and invasive Pacific oysters, Crassostrea gigas, reduced trematode infection load on native mussels, Mytilus edulis, in both single species and mixed species (both invasive species present) treatments (Thieltges et al. 2009). However, both of these experiments were conducted in mesocosms with simplified biotic interactions (Kopp and Jokela 2007, Thieltges et al. 2009).

We know of no field experiments that have tested the dilution effect under complex, natural conditions. Therefore, we conducted field experiments to determine whether native species benefit from reduced rates of trematode parasitism when $P$. antipodarum are present. This work is important because $P$. antipodarum have been shown to have variable effects on native species (e.g., Schreiber et al. 2002, Riley et al. 2008, Brenneis et al. 2010). If $P$. antipodarum provide some benefit to native snails through a dilution effect, potential negative effects on native snails could be partially ameliorated. $\downarrow \quad$ METHODS

We conducted field experiments in 2014 and 2015 to determine whether the presence of $P$. antipodarum reduces trematode infections in native snails. Each experiment had three experimental treatments: native snails only (control), native snails with the ambient biomass of invasive $P$. antipodarum snails, and native snails with double the ambient biomass of invasive snails. We assessed ambient biomass of $P$. antipodarum in Polecat Creek for each year by collecting four quantitative samples (stovepipe sampler) and using the mean biomass of all samples as the ambient biomass of $P$. antipodarum for that year.

In 2014, we placed native snails (Family Physidae or Pyrgulopsis idahoensis) and the treatment level of $P$. antipodarum into experimental chambers (modified square plastic sandwich containers (156.3 $\mathrm{cm}^{2}$ ) with mesh windows on the top and each side). The screen keeps snails in the chamber and allows fresh, oxygenated, water and the infective stage of trematodes into the chambers. The experiment with physid snails was conducted using floating platforms to keep the experimental chambers at the water-air interface since physids are pulmonate snails and require air for respiration. We attached the chambers housing $P$. idahoensis and treatments of $P$. antipodarum to bricks to anchor the chambers to the streambed. As a food source for the snails, we covered the bottom of each chamber with algae-covered pebbles from the stream. In 2014, eight replicates were created for each treatment in the two experiments.

We conducted the same experiment in the summer of 2015 in the same area of Polecat Creek, but reduced the period that the snails were exposed to trematode infection to 12 days instead of four weeks. 
Due to the high mortality of physid snails in the 2014 experiment, we used Fossaria sp. instead of physids. Fossaria sp. are also pulmonate snails and consequently were placed in experimental chambers in floating platforms in the 2015 experiment. In 2015, eight replicates were created for each treatment with the native Fossaria sp. while only seven replicates were possible for the experiment using $P$. idahoensis.

During both years, each experimental chamber was monitored twice a week to: 1) assess snail mortality, 2) clean screens of silt/debris and 3) replace algae covered pebbles. To reduce background infections in experimental snails, we shed all snails to determine infection status and only use uninfected snails in the experiments. At the end of each experimental period, we transported native snails to University of Wyoming where these snails were housed for sixteen weeks to allow adequate time for development of trematode infections. After sixteen weeks, we dissected all snails to determine trematode infection status.

Due to infiltration of cages by $P$. antipodarum resulting in non-discrete independent variables (treatments) and proportional dependent variables, we conducted logistic regressions between each dependent variable and $P$. antipodarum density for the 2014 experiments (Dalgaard 2002). Once final data collection has occurred for the 2015 data, we will analyze the data using logistic regressions to determine if density of $P$. antipodarum reduced trematode prevalence or trematode diversity in each native snail species.

\section{$\uparrow \quad$ RESULTS}

For the 2014 experiments, we found no effect of the density of $P$. antipodarum on infection rates of the native snail, $P$. idahoensis $(\mathrm{z}=0.847, \mathrm{p}=0.397$; Figure 1A). Trematode diversity and $P$. antipodarum density had a near significant relationship $(\mathrm{z}=-1.899$, $\mathrm{p}=0.058$ ) for the $P$. idahoensis experiment with trematode diversity decreasing with increased density of $P$. antipodarum (Figure 1B). Neither infection rate $(\mathrm{z}=-0.729, \mathrm{p}=0.466)$ nor trematode diversity $(\mathrm{z}=$ $0.621, \mathrm{p}=0.534$ ) had a significant relationship with $P$. antipodarum density in physid snails (Figure 2).

\section{$\uparrow \quad$ DISCUSSION}

Overall, the experiment in 2014 had no significant results between infection rates and $P$. antipodarum density. We believe the high infection rates for all treatments with the native species $P$. idahoensis (Figure 1A) were due to the high infection
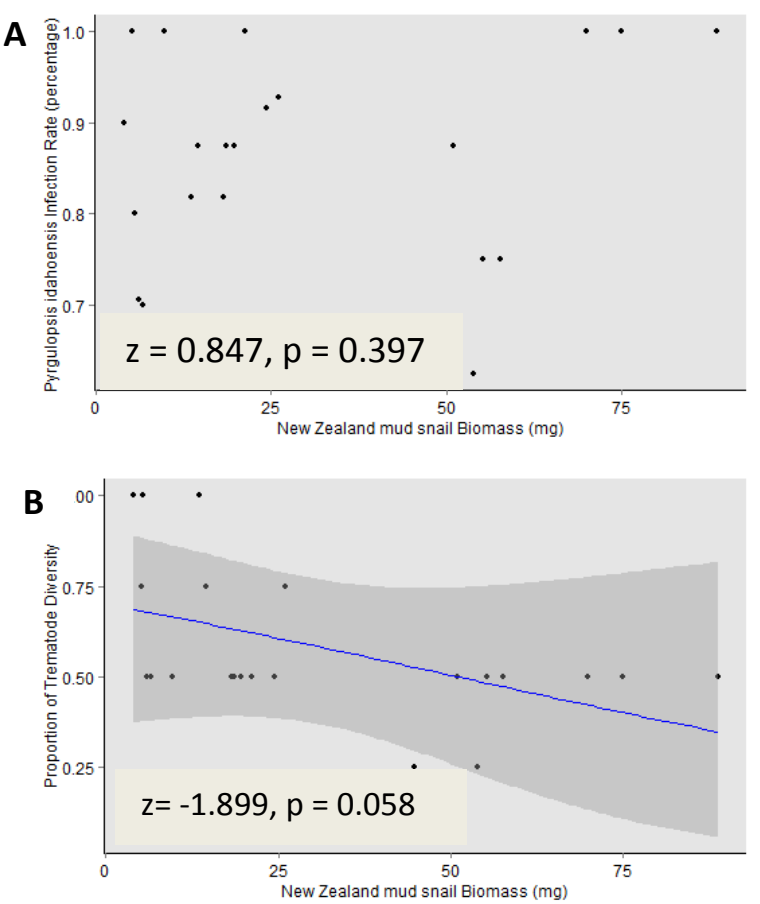

Figure 1. Relationship between New Zealand mud snail, $P$. antipodarum, biomass and Trematode prevalence (A) and Trematode diversity (B) in the native snail, Pyrgulopsis idahoensis.
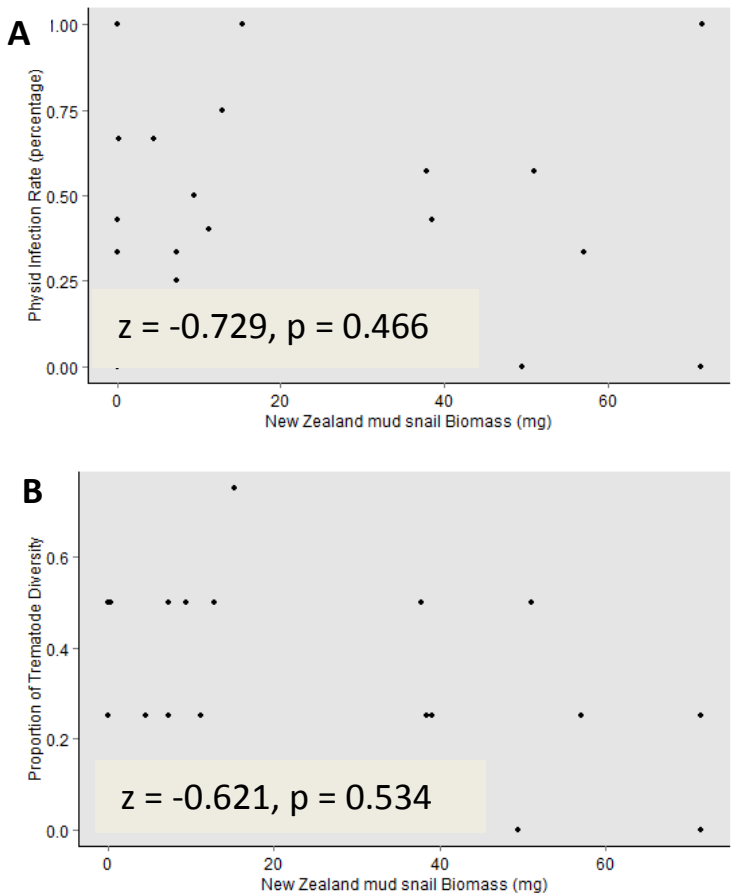

Figure 2. Relationship between New Zealand mud snail, $P$. antipodarum, biomass and Trematode prevalence (A) and Trematode diversity (B) in native physid snails. 
rates in the area of the stream so that nearly every $P$. idahoensis was infected, regardless of experimental treatment. The high mortality $(57.1 \%)$ in the stream of the native physid snails created many treatment replicates with less than 4 individuals which may have skewed the infection prevalence metrics to overestimate infection of physids. Consequently, the 2014 experiment did not accurately test the hypotheses of the dilution effect.

We are optimistic that once the data are analyzed for the 2015 experiments, a more accurate assessment of the dilution effect hypothesis will be possible.

\section{$\downarrow \quad$ ACKNOWLEDGMENTS}

We thank Daniel Greenwood and Kara Wise for field assistance. All research was conducted under the permission of the Wyoming Game and Fish Department (Chapter 33 Permit \#718) and Grand Teton National Park (Research permit \#GRTE-2014SCI-0039).

\section{$\downarrow \quad$ Literature CiTED}

Brenneis, V.E.F., A. Sih, and C.E. de Rivera. 2010. Coexistence in the intertidal: Interactions between non-indigenous New Zealand mud snail Potamopyrgus antipodarum and the native estuarine isopod Gnorimosphaeroma insulare. Oikos 119:1755-1764.

Dalgaard, P. 2002. Introductory Statistics with R. Springer, New York USA.

Johnson, P.T.J., and D.W. Thieltges. 2010. Diversity, decoys, and the dilution effect: How ecological communities affect disease risk. J Exp Biol 213:961-970.

Kopp, K., and J. Jokela. 2007. Resistant invaders can convey benefits to native species. Oikos 116:295-301.

Prenter, J., C. MacNeil, J.T.A. Dick, and A.M. Dunn. 2004. Roles of parasites in animal invasions. Trends in Ecol Evol 19:385-390.

Riley, L.A., M.F. Dybdahl, and R.O. Hall Jr. 2008. Invasive species impact: Asymmetric interactions between invasive and endemic freshwater snails. J. N. Am Benthol Soc 27:509-520.

Schreiber, E.S.G., P.S. Lake, and G.P. Quinn. 2002. Facilitation of native stream fauna by an invading species? Experimental investigations of the interaction of the snail, Potamopyrgus antipodarum (Hydrobiidae) with native benthic fauna. Biol Invasions 4:417-325.

Thieltges, D.W., K. Reise, K. Prinz, and K.T. Jensen. 2009. Invaders interfere with native parasitehost interactions. Biol Invasions 11:14211429. 